\title{
Improvement of Manufacturing Performance Measurement System and Evaluation of Overall Resource Effectiveness
}

\author{
Karuppana Gounder Eswaramurthi and Pidugun Venkatachalam Mohanram \\ Department of Mechanical Engineering, Faculty of Engineering, \\ PSG College of Technology, Anna University, Coimbatore-641 004, India
}

Received 2012-11-14, Revised 2013-01-07; Accepted 2013-03-16

\begin{abstract}
In the present highly competitive business environment, well run organizations continually strive to enhance their capabilities to create excellent value for the customers by improving the cost effectiveness of the operations. Significant improvement has taken place in the management of resources associated with manufacturing systems, to reduce the wastage of resources. The Total Productive Maintenance (TPM) concept provides a quantitative metric-Overall Equipment Effectiveness (OEE), for measuring the effectiveness of equipment or a production line. In this study, a method is developed to evaluate Overall Resource Effectiveness (ORE) by including the factors known as readiness, changeover efficiency, availability of material and availability of manpower. ORE addresses various kinds of losses associated with manufacturing system, which can be targeted for initiating improvements. Further, a case study is presented for the evaluation of ORE in a manufacturing line.
\end{abstract}

Keywords: Total Productive Maintenance, Total Productive Maintenance (TPM), Overall Equipment Effectiveness, Overall Resource Effectiveness, Overall Equipment Effectiveness (OEE)

\section{INTRODUCTION}

In today's global and highly competitive environment, it is essential for the survival of any firm to be adaptive, price competitive, responsive and proactive and has the capability to deliver world class products according to diverse customer requirements. These challenges force companies to implement various Lean tools to meet the needs of the ever-changing market demand. To be a worldclass organization and to be stable in the global market, the firm does not have to operate worldwide or even nationwide. It may be a small local organization, which leads in its area/fields embraces and actively demonstrates to the characteristics of world-class performance. Worldclass performance maintains, continued success through the development of an organizational environment that is distinctly different from peer and competitor firms in its philosophy and wealth-creating formula. A great number of companies find that in spite of huge improvements in productivity, there is still a bigger and better potential to utilize machine tools and reach better productivity goals. One of the main methods to meet these challenges is
Total Productive Maintenance (TPM). After TPM implementation, it is necessary to monitor the overall effectiveness of the manufacturing system and benchmark it with the World class standard which will enable to continuously improve and become a World class organization.

\subsection{Measurement of Effectiveness}

In a manufacturing scenario, the desirable productivity, quality, cost, delivery, safety and morale all depend on the effective functioning of the company's facilities. Metrics for measuring and analyzing the productivity of manufacturing facilities have been studied for several decades. Consequently, it is discovered that measurement is needed for identifying the problems in order to improve the productivity. To achieve this, it is necessary to establish appropriate metrics for measurement purposes (Nachiappan and Anantharaman, 2006). The TPM paradigm, launched by Nakajima (1988) in the 1980s, provided a quantitative metric for measuring the productivity of individual production equipment. 


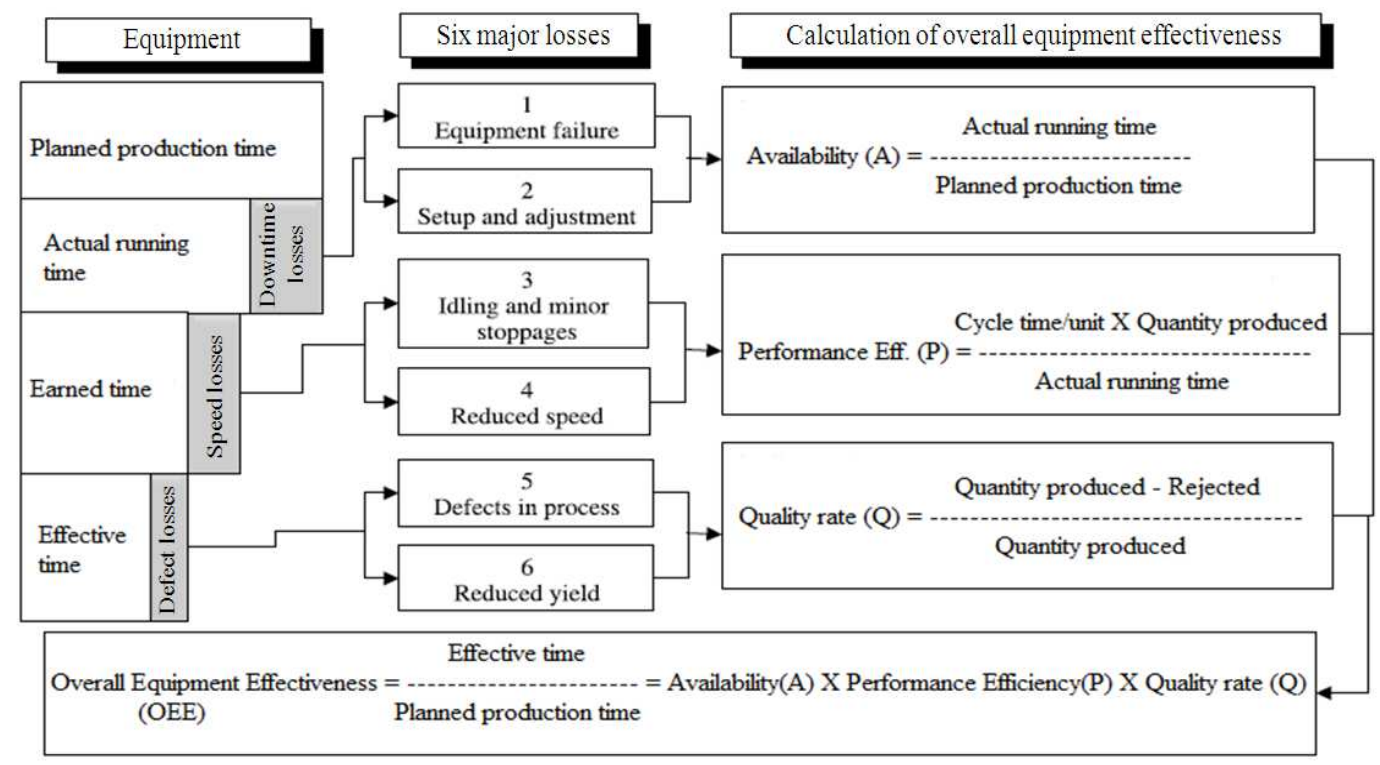

Fig. 1. Six major losses and Calculation of OEE

Table 1. Classification of six major losses

\begin{tabular}{ll}
\hline Losses & Definition \\
\hline Equipment failure & $\begin{array}{l}\text { Losses due to failures. Failure types include sporadic function stopping failures and function-reduction } \\
\text { failures in which the function of the equipment drops below the normal level }\end{array}$ \\
$\begin{array}{l}\text { Setup and adjustment } \\
\text { Minor stoppage }\end{array}$ & $\begin{array}{l}\text { Stoppage losses that accompany setup changeovers including adjustments for correct positioning } \\
\text { Losses that occur when the equipment temporarily stops or idles due to sensor actuation or jamming of the work. } \\
\text { The equipment will then operate normally through simple measures (removal of the work and resetting) }\end{array}$ \\
$\begin{array}{l}\text { Reduced speed } \\
\text { Defect/rework in process } \\
\text { Reduced yield }\end{array}$ & $\begin{array}{l}\text { Losses due to actual operating speed falling below the designed speed of the equipment } \\
\text { Losses due to defect and reworking of product }\end{array}$ \\
\hline
\end{tabular}

The metric, which is called Overall Equipment Effectiveness (OEE), is accepted as a measurement of internal efficiency (Johnson and Lesshammer, 1999) and it is the true measure of the value added production by equipment.

\subsection{Chronic and Sporadic Disturbances in Manufacturing}

It is very important to measure and understand the method of measurements of disturbances in the manufacturing process. Disturbances can, according to Tajiri and Gotoh (1992), roughly be divided into two categories, chronic and sporadic. Chronic disturbances are usually small, hidden and complicated since they are the result of several concurrent causes. Sporadic disturbances are more obvious since the deviations from the normal state are large. They occur irregularly and their dramatic effects are considered to lead to serious problems, but instead there are chronic disturbances that result in the low utilization of equipment and large costs because they occur repeatedly. Chronic disturbances are more difficult to identify since they can be seen as the normal state and are inherent in the system of manufacturing.

Chronic and sporadic disturbances in the manufacturing process result in different kinds of waste or losses which absorb resources but create no value. The objective of OEE is to identify these losses. It is essentially a bottom-up approach where an integrated workforce strives to achieve OEE by eliminating the six big losses (Nakajima, 1988).

\subsection{Overall Equipment Effectiveness (OEE) and Six Major Losses}

The OEE measure can be applied at different levels within a manufacturing environment. OEE does not diagnose (Costa and Lima, 2002) a specific reason why a machine is not running as efficiently as possible, but it helps to categories the areas for initiating the equipment improvement. OEE can be used as a "benchmark" for 
comparing the initial and improved performance of a manufacturing plant, thus quantifying the level of improvement made.

The effectiveness of a plant's production depends on the effectiveness with which it uses equipment, materials, man and methods (Suzuki, 1994). Improving production effectiveness, therefore, starts with the inputs to the production process (Man, Machine, material and methods) and identification and elimination of the losses associated with each to maximize the outputs.

According to Nakajima (1988), OEE measurement is an effective way of analyzing effectiveness of the equipments in the manufacturing system. OEE is usually formulated as a function of number of mutually exclusive parameters such as availability, performance efficiency and quality rate. The losses which reduce the effectiveness of the equipments are divided into six major categories (Nakajima, 1988), as shown in the Table 1.

The first two losses (Table 1) are defined as time losses, affect the Availability of equipment. The third and forth losses are speed losses that affect the Performance efficiency of an equipment. The last two losses are quality losses; these losses directly affect the Quality rate of equipment. Based on the above six losses, the Availability, Performance, Quality rate and OEE (Nakajima, 1988; Blanchard, 1997; Eti et al., 2004) can be calculated. The structure of losses, OEE and its factors are shown in Fig. 1.

Dal et al. (2000) describe that OEE appears so differently in various OEE literatures as to reveal what levels of Availability, Performance efficiency and Quality rate constitute acceptable levels of OEE. They illustrate that OEE achievement or the level setting is different across different business sectors and industries. All these studies reveal that OEE is used as an index for performance evaluation of a manufacturing system. Chan et al. (2004) suggest that, although OEE is seen to be the standard method for the measurement of equipment performance, it still requires further modification on classification of losses.

\subsection{Problem Background}

An industry can always consist of many equipments/product lines based on their market position, customer requirement and technical capability available in the firm. The product must move in a sequential manner according to the layout of the machines (processing equipments) as per the product routing. First, the raw material enters process- 1 , then process- 2 and then proceeds till to the final process, through ' $n$ ' processes. Each process/manufacturing line utilizes the resources such as Man, Machine (includes Jigs and Fixtures and Gauges and Instruments), Material whose performance needs to be improved rather than concentrating only on machines.

\subsection{The Problem}

According to Nakajima (1988); Bamber et al. (2003) and Dal et al. (2000), Availability, Performance and Quality rate are the factors for calculation of Overall Equipment Effectiveness (OEE). Bamber et al. (2003) observe that OEE is often used as a driver for improving the performance of a business by concentrating on quality, productivity and machine utilization issues and, hence, it is aimed at reducing non-value adding activities often inherent in manufacturing processes. According to the classification of losses given by Jeong and Phillips (2001), down time including Set-up and adjustments is included within the availability losses. According to Johnson and Lesshammar (1999) the availability rate measures the total time that the system is not operating because of breakdowns, set-up and adjustment and other stoppages. This classification of losses includes all the down time events (equipment and process related) into one category and leads to the factor of availability, hampering the identification of losses in stratified manner. In addition to that, if planned down time is not taken into account in calculation of effectiveness which leads to excessively long planned activities.

The next problem in OEE calculation is there is no separate metric or method to monitor the losses due to non-availability of manpower and material (components, sub-assemblies and WIP) which are also extremely important for effectiveness of a manufacturing system.

The existing OEE factors are not sufficient for assessment of losses individually in a manufacturing system. Hence, an attempt has been made in this study to address the losses associated with manufacturing resources with separate metrics which enable the engineers and managers to initiate the improvement action on the specific metrics/losses.

\section{MATERIALS AND METHODS}

\subsection{Proposed Method}

The proposed method of effectiveness calculation differs from the existing one and new factors known as Readiness, Availability of Facility, Changeover Efficiency, Availability of Material, Availability of Man power are included in the calculation. Finally the existing term Overall Equipment Effectiveness (OEE) is modified as Overall Resource Effectiveness (ORE) since the new methodology addresses the losses associated with the resources (man, machine, material, method) individually. Inclusion of these new factors, enable us to more detailed and stratified classification of the resource losses. The proposed classification of losses (Table 2) and the Overall Resource Effectiveness Model (ORE) (Fig. 2) are shown and the evaluation of Overall Resource Effectiveness (ORE) is presented. 


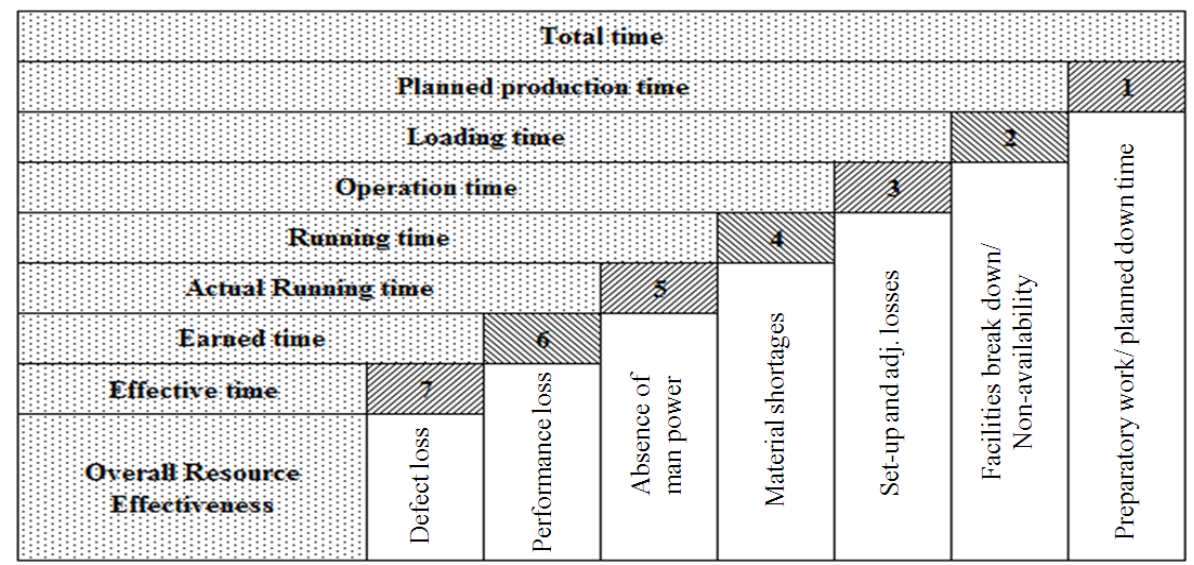

Fig. 2. Overall Resources Effectiveness (ORE) Model

Table 2. Proposed classification of losses

\begin{tabular}{ll}
\hline ORE factors & Proposed classification of losses \\
\hline Readiness & Losses due to preparatory on machine or facilities/Planned down time \\
Availability of facility & Losses due to equipment and accessories break down, Break down/non- availability of Machine \\
& accessories, Tools, Jigs and Fixtures, Gauges and instruments, etc., related to facility \\
Changeover efficiency & Losses due to Set-up and adjustments \\
Material availability & Losses due to non-availability of raw material/components / sub-assembly/WIP \\
Man power availability & Losses due to non-availability/absence of Manpower \\
Performance efficiency & Losses due to operator performance, speed loss and ergonomic related issues \\
Quality losses & Losses due to quality issues/defects \\
\hline
\end{tabular}

\subsection{Evaluation of Overall Resource Effectiveness (ORE)}

The factors including new factors (Readiness, Availability of Facility, Changeover Efficiency, Availability of Material, Availability of Man power) and the inputs required for evaluation of ORE are presented below.

\subsection{Readiness (R)}

The "Readiness (R)" measure is concerned with the total time that the system is not ready for operation because of planned down time due to preparatory/ planned activities. Readiness indicates the ratio of planned production time to the total time available:

$$
\text { Readiness }(\mathrm{R})=\frac{\text { Planned production time }}{\text { Total time }}
$$

Total time

$=$ Shift time or period decided by the management

Planned production time $=($ Total time-Planned down time)

Planned down time includes:

- Preparatory work like cleaning, inspection of machine, initial part inspection, lubrication, tightening, Data collection and updation
- $\quad$ Meeting, Audit, operator training

- Proto sample processing for R and D requirements, Process engineering study

\subsection{Availability of Facility $\left(A_{f}\right)$}

The "Availability of Facility $\left(\mathrm{A}_{\mathrm{f}}\right)$ " measure is concerned with the total time that the system is not operating due to down time of facilities. It indicates the ratio of loading time to the planned production time:

$$
\text { Availability of facility }\left(A_{f}\right)=\frac{\text { Loading time }}{\text { Planned production time }}
$$

Loading time $=$ Planned production time-Facilities down time.

Facilities down time includes:

- Down time of machine and its accessories

- Non-availability of tools, jigs and fixtures

- Non-availability of gauges and instruments, test rigs related to facility

\subsection{Changeover Efficiency (C)}

The Changeover Efficiency (C) measure is concerned with the total time that the system is not operating because of Set-up and adjustments. It indicates the ratio of operation time to the Loading time: 


$$
\text { Changeover efficiency }(C)=\frac{\text { Operation time }}{\text { Loading time }}
$$

Operation time $=$ Loading time-Set-up and adjustments.

Set-up and adjustments include:

- Changeover time of tools, dies, jigs and fixtures

- Minor adjustments after the changeover

\subsection{Availability of Material $\left(A_{m}\right)$}

In manufacturing scenario, sometimes, the raw materials, components, sub-assemblies are not available due to shortages and various other reasons. The "Availability of Material $\left(\mathrm{A}_{\mathrm{m}}\right)$ " measure is concerned with the total time that the system is not operating because of material shortages. It is the ratio of running time to the operation time.

$$
\text { Availability of material }\left(A_{m}\right)=\frac{\text { Running time }}{\text { Operation time }}
$$

Running time $=$ Operation time-Material shortages

Material shortage includes:

- Non-availability of raw materials, consumables, parts and sub-assemblies

- Non-availability of WIP

\subsection{Availability of Manpower ( $\left.A_{m p}\right)$}

In manufacturing system, sometimes, the operator/s may not be available at work station due to absenteeism, discussions. The "Availability of Manpower $\left(\mathrm{A}_{\mathrm{mp}}\right)$ " measure is concerned with the total time that the system is not operating because of absence of manpower. It is the ratio of Actual running time to the Running time:

$$
\text { Availability of manpower }\left(\mathrm{A}_{\mathrm{mp}}\right)=\frac{\text { Actual running time }}{\text { Running time }}
$$

Actual Running time $=$ Running time-Manpower absence time.

Man power absence includes:

- Permission, Leave and absenteeism

- Discussion with supervisor, team leader

- Medical related

\subsection{Performance Efficiency (P)}

The "Performance efficiency (P)" measures the total time that the operator how efficiently utilizes. It is the time earned in producing the product as against the Actual running time. Performance efficiency is the ratio of Earned time to the Actual running time.

$$
\text { Performance efficiency }(P)=\frac{\text { Earned time }}{\text { Actual running time }}
$$

Earned time $=$ Cycle time/unit X Quantity produced.

\subsection{Quality Rate (Q)}

The "Quality rate" is the rate of quality products produced by the system. It is the ratio of Quantity of parts accepted to the Quantity of parts produced:

$$
\text { Quality rate }(\mathrm{Q})=\frac{\text { Quantity of parts accepted }}{\text { Quantity of parts produced }}
$$

Quantity of parts accepted = Quantity produced-Quantity rejected.

\subsection{Overall Resource Effectiveness (ORE)}

The "Overall Resource Effectiveness (ORE)" is the measure of overall effective time of the manufacturing system (resources). It is the product of Readiness (R), Availability of Facility $\left(\mathrm{A}_{\mathrm{f}}\right)$, Changeover Efficiency $(\mathrm{C})$, Availability of Material $\left(\mathrm{A}_{\mathrm{m}}\right)$, Availability of Man power $\left(\mathrm{A}_{\mathrm{mp}}\right)$, Performance Efficiency $(\mathrm{P})$ and Quality rate $(\mathrm{Q})$.

Overall Resource Effectiveness (ORE) = Readiness (R) $\mathrm{X}$ Availability of Facility $\left(\mathrm{A}_{\mathrm{f}}\right) \mathrm{X}$ Changeover Efficiency (C) X Availability of Material $\left(\mathrm{A}_{\mathrm{m}}\right) \quad \mathrm{X}$ Availability of Man power $\left(\mathrm{A}_{\mathrm{mp}}\right) \mathrm{X}$ Performance Efficiency (P) X Quality rate (Q) X 100:

$$
\mathrm{ORE}=\mathrm{R} \times \mathrm{A}_{\mathrm{f}} \times \mathrm{C} \times \mathrm{A}_{\mathrm{m}} \times \mathrm{A}_{\mathrm{mp}} \times \mathrm{P} \times \mathrm{Q} \times 100
$$

ORE will be much helpful to the decision maker for further analysis and continually improve the performance of the resources. This is used to identify the current status of manufacturing system and also for benchmarking the manufacturing effectiveness with the World class standard to become a World class organization.

Table 3. Operational performance data collected

\begin{tabular}{lr}
\hline Description & Time in minutes \\
\hline Total time & 148100 \\
Planned down time & 8950 \\
Planned production time & 139150 \\
Facilities down time & 7030 \\
Loading time & 132120 \\
Set-up and adjustments time & 4790 \\
Operation time & 127330 \\
Material non-availability time & 11740 \\
Running time & 115590 \\
Manpower non-availability & 2690 \\
Actual running time & 112900 \\
Earned time & 88505 \\
Quantity of parts produced & 4658 \\
\hline
\end{tabular}


K.G. Eswaramurthi and P.V. Mohanram / American Journal of Applied Sciences, 10 (2): 131-138, 2013
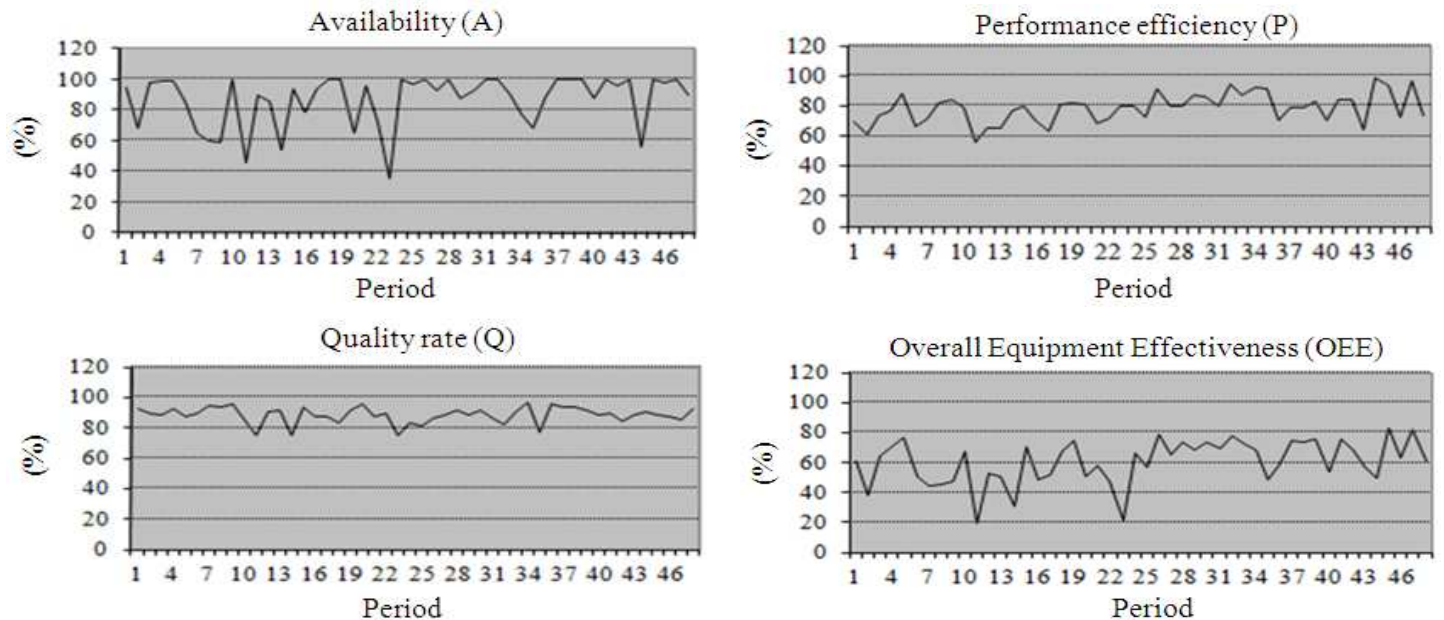

Fig. 3. Dash board of Overall Equipment Effectiveness (OEE)
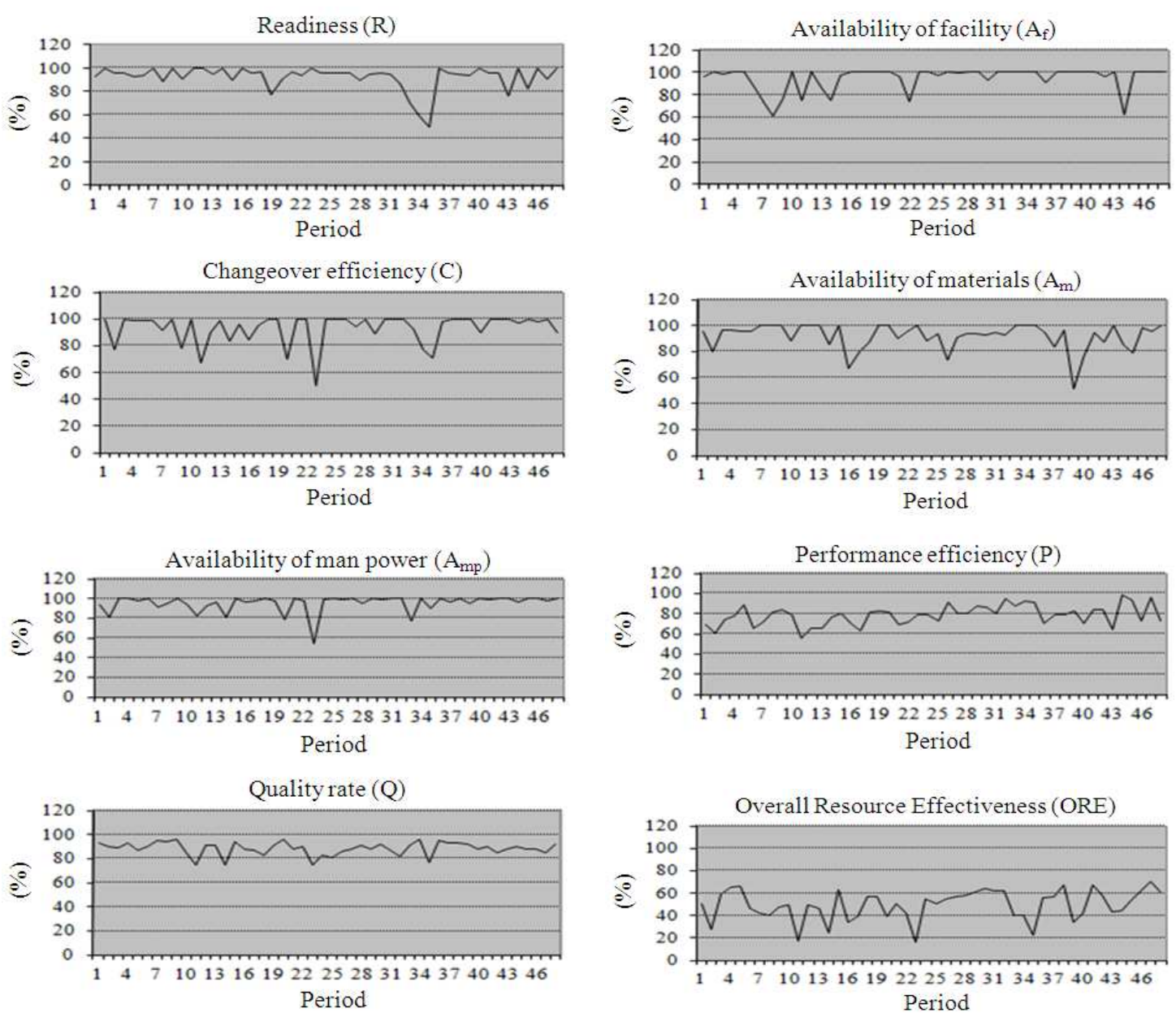

Fig. 4. Dash board of Overall Resource Effectiveness (ORE) 
Table 4. Comparison of OEE and ORE

\begin{tabular}{llc}
\hline Effectiveness factors & Nakajima classification (OEE) & Proposed classification (ORE) \\
\hline Readiness & -- & $93.96 \%$ \\
Availability of facility & -- & $94.95 \%$ \\
Availability & $81.14 \%$ & -- \\
Changeover efficiency & -- & $96.37 \%$ \\
Availability of material & -- & $90.78 \%$ \\
Availability of man power & -- & $97.67 \%$ \\
Performance efficiency & $78.39 \%$ & $78.39 \%$ \\
Quality rate & $88.73 \%$ & $88.73 \%$ \\
Overall effectiveness & $56.44 \%$ (OEE) & $53.02 \%($ ORE) \\
\hline
\end{tabular}

\subsection{Case Study}

A case-based approach is used to illustrate the proposed method of Overall Resource Effectiveness (ORE) calculation. A major product of a manufacturing company is considered for the study. The application of ORE and its factors within this environment is presented.

In order to start the ORE measurement process, operational performance data collection for seven ORE variables viz., Readiness, Availability of Facility, Changeover Efficiency, Availability of Material, Availability of Man power, Performance Efficiency and Quality rate was carried out and presented in Table 3.

The Overall Equipment Effectiveness (OEE), Overall Resource Effectiveness (ORE) and their factors are calculated and tabulated in Table 4.

The Fig. 3 and 4 shows the Dash board of OEE and ORE respectively for monitoring and better understanding of various losses which would be used to take improvement actions on each category.

\section{RESULTS}

The proposed method provides the complete information on various losses additionally in a stratified way to initiate appropriate action for improvement.

The trend of various factors of ORE are shown in the ORE Dash Board (Fig. 4) which is very much useful for monitoring the losses on a continuous basis and base for further improvement.

\section{DISCUSSION}

OEE factors do not provide the planned production time losses with separate metric where there is scope for improvement. Readiness in ORE provides the losses on account of planned production time.

OEE shows the mainly the uptime of machine, but ORE considers the whole facility like Machines, Tools, Jigs and Fixtures and Gauges and instruments.
ORE shows the stratified lost time of Set-up and adjustments which can be improved by using SMED (Single Minute Exchange of Dies) concept.

Many companies are facing the materials and component shortages. The factor Availability of Materials addresses the material shortage separately to initiate action on the external and internal suppliers.

Operator leave and absenteeism is also addressed including small portion of absence due to discussion with supervisors and team leaders. Operators can be motivated to reduce leave and absenteeism.

In addition to the above, action can be initiated for improvement of Performance Efficiency and Quality rate to enhance the ORE continually.

\section{CONCLUSION}

This study presents the developed Overall Resources Effectiveness methodology for performance measurement. The measurement of ORE leads to the focused improvement required to enhance the effectiveness of manufacturing system. ORE provides a useful guide to aspects of the production process where losses can be targeted which are created by the resources. In order to utilize the ORE measure effectively, it must be made convincing and possible to manufacturing environment. For this, the real effectiveness of the manufacturing system is calculated fully using the method developed and presented in this study. The effectiveness measurement using ORE is good enough to improve the effectiveness of resources. The results of the study show that the proposed method of ORE will be helpful for today's organizations to initiate improvement activities towards enhancing the overall performance of resources by identifying the problem exactly (based on the proposed factors) and thus achieve business excellence by effective utilization of the available resources. Further, the metric ORE can be used as a benchmark at various levels to achieve world-class standard. 


\section{REFERENCES}

Bamber, C.J., P. Castka, J.M. Shrp and Y. Motara, 2003. Cross-functional team working for Overall Equipment Effectiveness (OEE). J. Q. Maintenance Eng., $\quad$ 9: 223-238. $10.1108 / 13552510310493684$

Blanchard, B.S., 1997. An enhanced approach for implementing total productive maintenance in the manufacturing environment. J. Q. Maintenance Eng., 3: 69-80. DOI: 10.1108/13552519710167692

Chan, F.T.S., H.C.W. Lau, R.W.L. Ip, H.K. Chan and S. Kong, 2004. Implementation of total productive maintenance: A case study. Int. J. Prod. Econ., 95: 71-94. DOI: 10.1016/j.ijpe.2003.10.021

Costa, S.E.G.D. and E.P.D. Lima, 2002. Uses and misuses of the 'overall equipment effectiveness' for production management. Proceedings of the IEEE International Engineering Management Conference, (IEMC' 02), Catolica Do Parana, Curitiba, Brazil, pp: 816-820. DOI: 10.1109/IEMC.2002.1038543

Dal, B., P. Tugwell and R. Greatbanks, 2000. Overall equipment effectiveness as a measure of operational improvement-A practical analysis. Int. J. Operat. Prod. Manage., 20: 1488-1502. DOI: $10.1108 / 01443570010355750$

Eti, M.C., S.O.T. Ogaji and S.D. Probert, 2004. Implementing total productive maintenance in Nigerian manufacturing industries. Applied Energy, 79: 385-401. DOI: 10.1016/j.apenergy.2004.01.007
Jeong, K.Y. and D.T. Philips, 2001. Operational efficiency and effectiveness measurement. Int. J. Operat. Prod. Manage., 21: 1404-1416. DOI: 10.1108/EUM0000000006223

Johnson, P. and M. Lesshammer, 1999. Evaluation and improvement of manufacturing performance measurement systems-the role of OEE. Int. J. Operat. Prod. Manage., 19: 55-78. DOI: 10.1108/01443579910244223

Nachiappan, R.M. and N. Anamtharaman, 2006. Evaluation of Overall Line Effectiveness (OLE) in a continuous product line manufacturing system. J. Manufact. Technol. Manage., 17: 987-1008. DOI: $10.1108 / 17410380610688278$

Nakajima, S., 1988. Introduction to TPM. 1st Edn., Productivity Press, Cambridge, ISBN-10: 0915299232, pp: 129.

Suzuki, T., 1994. TPM in Process Industries. 1st Edn., Productivity Press, Portland, ISBN-10: 1563270366 , pp: 391.

Tajiri, M. and F. Gotoh, 1992. TPM Implementation: A Japanese Approach. 1st Edn., McGraw-Hill, New York, ISBN-10: 0070628343, pp: 328. 